\title{
Synthesis of new molecular systems
}

\author{
W. E. Billups, Weimei Luo, Dianne McCord, and Robert Wagner \\ Department of Chemistry, Rice University Houston, Texas 77251
}

\begin{abstract}
The versatile cyclopropene synthon 1-bromo-2-chlorocyclopropene has been used to synthesize new di- and tricycloproparenes. Treatment of these cycloproparenes with silver ion in chloroform leads to rapid oligomerization via carbocation intermediates to give materials in which the aromatic systems are connected by six-membered rings. The ladder polymer formed by treating the linearly fused dicyclopropanaphthalene with silver ion in chloroform has been characterized by solid state nuclear magnetic resonance spectroscopy.
\end{abstract}

The manufacture and manipulation of structures at the molecular level have been recognized as important goals for more than thirty years (1). The synthesis of linear rigid molecules composed primarily of six-membered rings (molecular lines) is of interest in this regard. Miller and his co-workers have prepared short molecular lines composed of polyacenequinone units via repetitive Diels-Alder reactions $(2,3)$. The Diels-Alder reaction has also been identified as a route to other novel belts or collars (4-9). In this manuscript we summarize our recent work on the synthesis of six-membered rings using cycloproparenes (10) as starting materials.

The reaction is exemplified below using the simplest cycloproparene, benzocyclopropene 1. Other examples in which benzocyclopropenes have been dimerized by silver ion in chloroform to yield dimers connected by six-membered rings are presented in Table 1 .
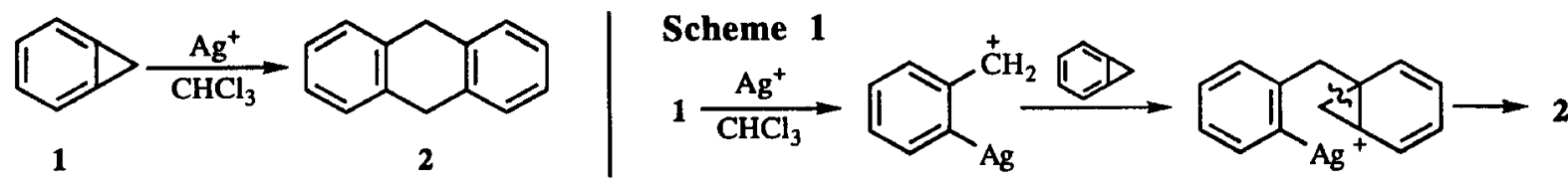

In a typical experiment a solution of the cycloproparene in anhydrous chloroform is added dropwise to a stirred suspension of $\mathrm{AgBF}_{4}\left(\approx 1\right.$ mole \%) in anhydrous chloroform at $0{ }^{\circ} \mathrm{C}$. The reaction is usually complete after a few minutes. A proposed mechanism is illustrated in Scheme 1.

The facile cleavage of the three-membered ring of benzocyclopropenes (11) by silver ion can be attributed to the strain energy associated with the cycloproparene ring system which has been estimated as $\approx 68 \mathrm{kcal} / \mathrm{mole}(12)$. The regiochemistry of these cleavage reactions may be understood in terms of the arguments presented by Garratt and his co-workers (13) who have studied the reactions of several asymmetrically fused benzocyclopropenes with electrophiles. Their studies showed that fusion of a second strained ring leads to regioselective cleavage of the cyclopropene ring. The product ratios for the dimerization reactions presented in Table 1 may be explained, at least in part, in terms of these arguments. Thus fusion of either a four or a five-membered ring to the benzocyclopropene gives predominately syn products whereas fusion of the unstrained six-membered ring gives mainly the anti isomer. Steric effects may also be important in the predominant formation of the anti dimer when benzocyclopropene is fused to a six-membered ring.

Aromatization of the dimers presented in Table 1 provides a convenient synthesis of the corresponding acenes. For example, treatment of 3 with DDQ in benzene for 1 hour yields anthracene 4 in $87 \%$ yield (10).<smiles>c1c2c(cc3c1Cc1cc4c(cc1C3)CC4)CC2</smiles>

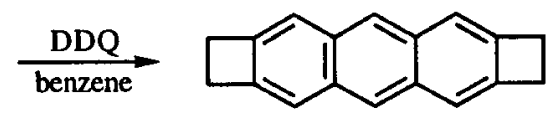




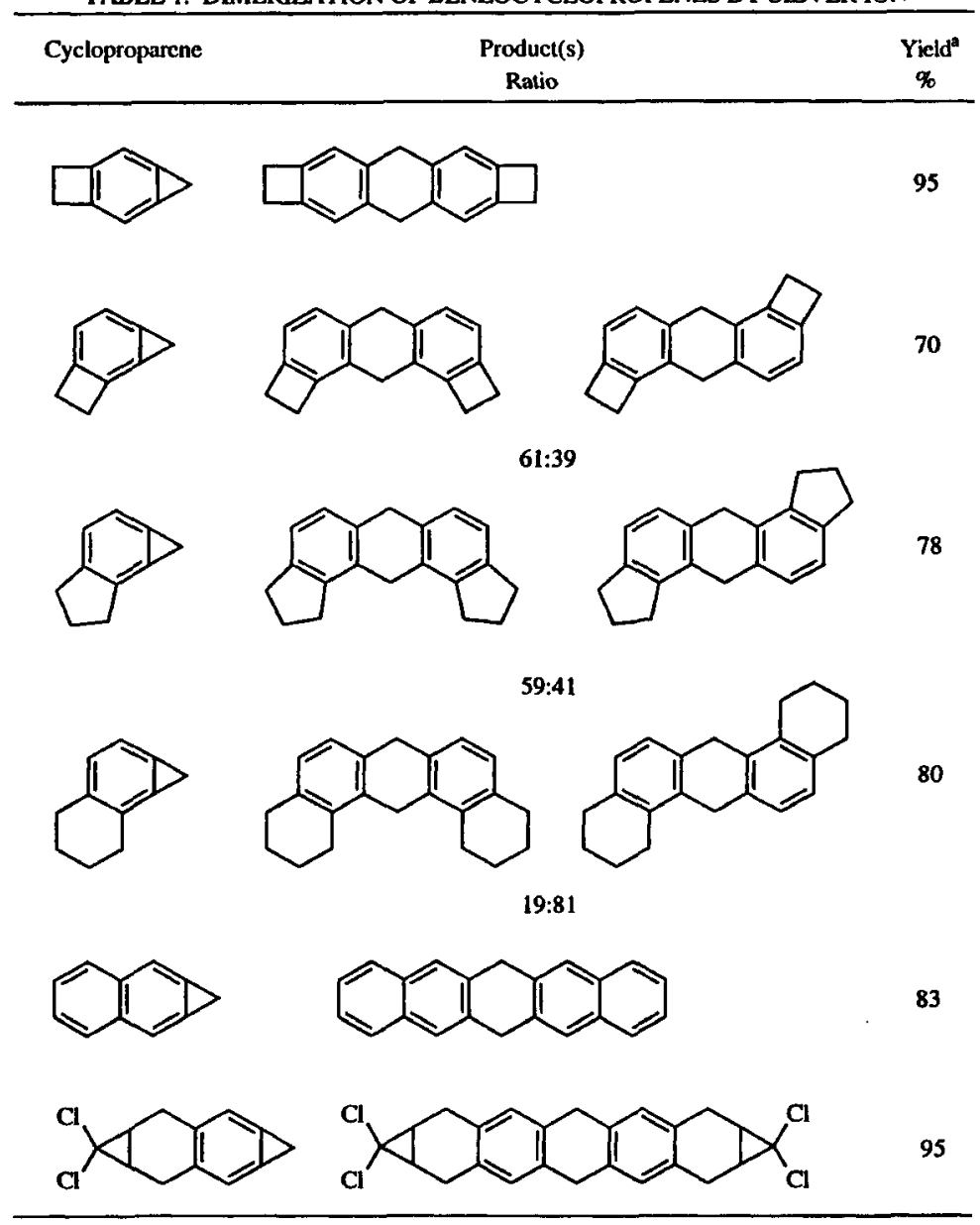

Yields are isolated yields and are combined yields for those reactions which yield two products.

The prospect that the polyacenes, or highly conjugated ladder polymers (14), might exhibit interesting electrical properties including unusual one-dimensional conductivity (15) has led to a flurry of activity in this area $(14,16-22)$. Simple iterative chain-growing reactions using bicycloproparenes $(23$, 24) should lead to materials which upon aromatization would yield these polyacenes.

We have investigated the oligomerization of 5 (23) using silver ion and we find that polymerization does occur. The reaction can be monitored by ${ }^{1} \mathrm{H}$ NMR spectroscopy in $\mathrm{CDCl}_{3}$ and the initially formed dimer 6 can be isolated readily by column chromatography.<smiles></smiles>

5

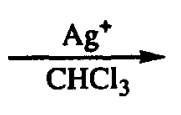<smiles></smiles>

6

As the chain length increases in size, the oligomers begin to precipitate. Characterization of the resulting thermally stable oligomers has been achieved to some extent by solid state nuclear magnetic resonance spectroscopy. The cross-polarization experiment revealed aromatic signals at 132.3 and 126.1 ppm and one signal at $37.0 \mathrm{ppm}$ which can be assigned to the saturated carbons.<smiles></smiles>

Unfortunately, the base-induced elimination-isomerization reaction of gem-dihalocyclopropanes used to synthesize 5 cannot be applied to the synthesis of cycloproparenes higher than the cyclopropanaphthalenes. However, we have found that the versatile cyclopropene synthon 1-bromo-2chlorocyclopropene $7(25)$ can be used to synthesize many of the higher cycloproparenes $(26)$. The cyclopropene itself can be synthesized readily from 8 either in solution or in the gas phase using fluoride salts to effect the elimination. 
<smiles>ClC1(Cl)CC1(Br)Br</smiles>

8

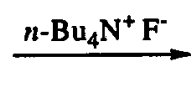

9 is illustrated in Scheme 2. The Diels-Alder adduct 10, prepared by allowing 7 and the tetraene $11(27)$ to stand at $-20{ }^{\circ} \mathrm{C}$ for several days, could be converted to the starting material 12 by aromatization using DDQ. The elimination of 12 using potassium $t$-butoxide in tetrahydrofuran yielded the desired cycloproparene.

Scheme 2<smiles>C=C1CCC(=C)C(=C(C)C2CC2Br)C1=C</smiles>

11<smiles>[X]C12CC(CC3=C1CC([X])([X])C([X])(C)C3)C(C)(C)C2</smiles>

$10 \mathrm{X}=\mathrm{Br}$ or $\mathrm{Cl}$<smiles>[X]C1([X])CCc2ccc3c(c2C1)CC([X])(CC)C([X])([X])C3</smiles>

12<smiles>c1ccc2cc3c(cc2c1)CC3</smiles>

9

Dimerization of 9 using silver ion in chloroform as described above for 5 was observed by nuclear magnetic resonance spectroscopy to give dimers 13 and 14 after only 5 minutes at $25^{\circ} \mathrm{C}$.<smiles></smiles><smiles>c1cc2ccc3cc4c(Cc5cc6cc7c(C8CC8)cc6cc57)cc3c2cc1C4</smiles>

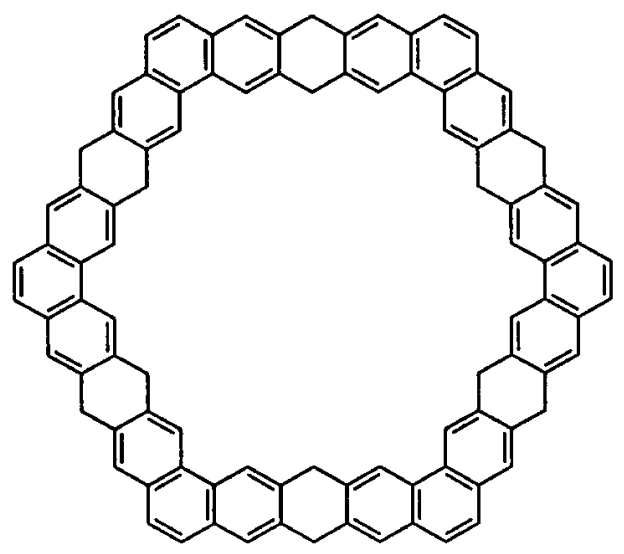

15

Prolonged reaction gave new materials provisionally identified as the zig-zag structures (molecular trails) illustrated in the equation. Cyclic structures such as $\mathbf{1 5}$ have not been isolated, although experiments to generate these compounds are still in progress.<smiles>CC(C)(C)C(C)(C)C</smiles>

Dicyclopropanthracene 16 has been synthesized (24) by treating the the Diels-Alder adduct of 7 and 1,2,4,5-tetramethylenecyclohexane with 2,3-dichloro-5,6-dicyanobenzoquinone followed by dehydrohalogenation using potassium $t$-butoxide in tetrahydrofuran as illustrated in Scheme 3.

\section{Scheme 3}<smiles>C=C1CC(=C)C(=C)CC1=C</smiles><smiles>[X]C1([X])CC2=C(C1)C([X])([X])CC1CC3=C(CC1=C2)CC1([X])CC1([X])C3</smiles><smiles>CCCCCCCC</smiles><smiles>[X]C1([X])Cc2cc3c(cc2C1)CC([X])(C)C([X])([X])C3</smiles>
$\mathrm{X}=\mathrm{Br}$ or $\mathrm{Cl}$<smiles>C1=c2cc3cc4c(cc3cc2=C1)C4</smiles> 
In contrast to 9, dicyclopropanthracene gave only insoluble oligomers. No evidence for the expected dimer as observed for 5 and 9 could be found under the conditions used for the oligomerization reaction.<smiles></smiles>

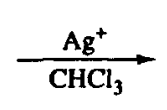<smiles>Cc1cc2cc3cc4c(cc3cc2cc1C)-c1cc2cc3cc(C)c(C)cc3cc2cc1C4</smiles>

16

The versatile cycloproparene synthon 1-bromo-2-chlorocyclopropene (25), has also also been used as a reagent in a key step during the synthesis of the novel dicycloproparene 17 (Scheme 4). The starting material 18 required for this synthesis was prepared by the Diels-Alder addition of 7 to the tetraene 19 (28). Elimination of $\mathbf{1 8}$ using potassium $t$-butoxide in tetrahydrofuran proceeded smoothly to yield the desired dicycloproparene.

Scheme 4

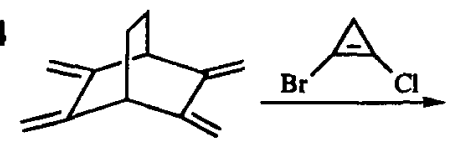

19

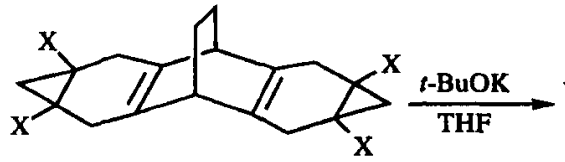

$18 \mathrm{X}=\mathrm{Br}$ or $\mathrm{Cl}$

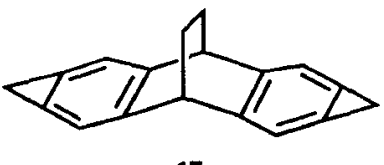

17

Studies on the oligomerization of $\mathbf{1 7}$ are still in progress. However, we have observed that silver ion induces rapid polymerization of the cycloproparene to yield dimers and as yet unidentified oligomers.

Tricycloproparenes such as $\mathbf{2 0}$ and $\mathbf{2 1}$ have only recently been reported (29). These compounds are of interest as precursors to graphitic-like networks with holes in the case of 20 or as honeycomb structures from 21.

The synthesis of $\mathbf{2 0}$ is presented in Scheme 5. Conversion of the mixture of regio isomers obtained from the reaction of hexaradialene (30) with 7 was carried out at $-50{ }^{\circ} \mathrm{C}$. Purification of the white solid could be achieved readily by flash column chromatography on neutralized Florisil.<smiles>C1=C2CC2c2cc3cc4c(cc1c-3c2)=c1cc2c(cc1=4)CC2</smiles>

20

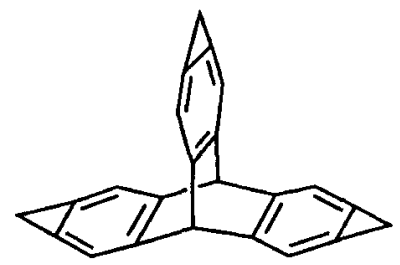

21
Scheme 5

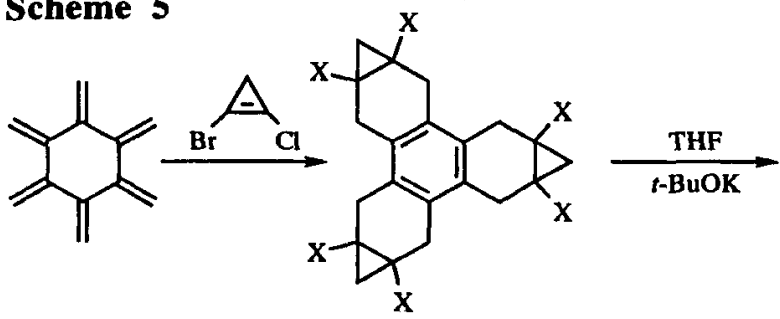

$\mathrm{X}=\mathrm{Br}$ or $\mathrm{Cl}$

The synthesis of 21 is presented in Scheme 6. The starting material 22 could be prepared by repetitive addition of 1-bromo-2-chlorocyclopropene to hericene (31). The elimination of 22 could not be effected using potassium $t$-butoxide in tetrahydrofuran as described for the synthesis of 20; however, a mixture of $\mathrm{N}, \mathrm{N}$-dimethylformamide, hexamethylphosphoramide $(5: 1)$ and potassium $t$-butoxide at room temperature under an atmosphere of nitrogen provided a suitable medium to carry out this reaction.

The cycloproparene could be isolated as a white solid in $\approx 50 \%$ yield. The triscycloproparenes were observed to undergo rapid oligomerization under the influence of silver ion in chloroform to yield insoluble polymers. Studies on the structure of these materials are under investigation.

\section{Scheme 6}

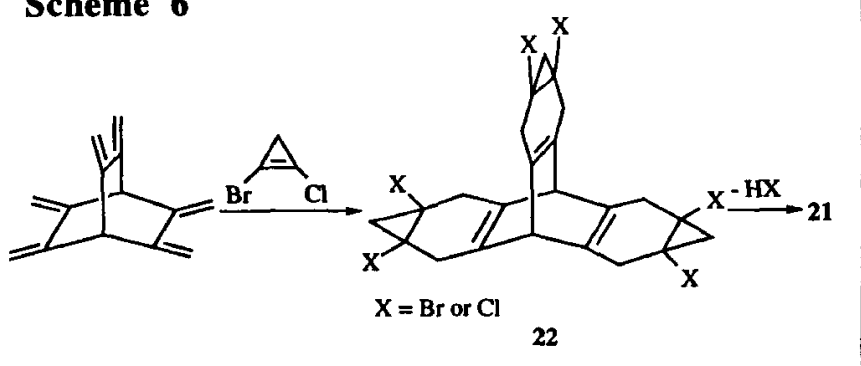

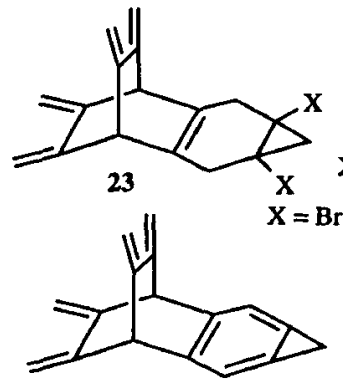

25

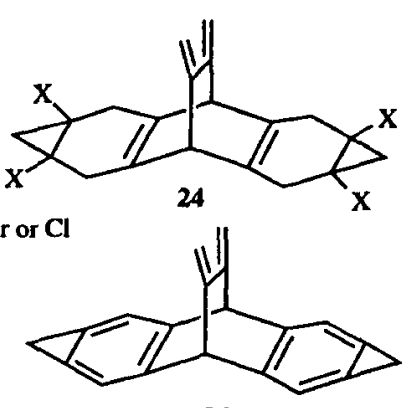

26

The Diels-Alder adducts 23 and 24 were also isolated from the reaction of hericene with 1-bromo2-chlorocyclopropene. These compounds could be converted to the cycloproparenes 25 and 26 , respectively, using potassium $t$-butoxide dissolved in the same $\mathrm{N}, \mathrm{N}$-dimethylformamidehexamethylphosphoramide medium used to synthesize 21. 
Fusion of benzocyclopropenes to paracyclophanes is of interest since the resulting cycloproparenes would have an orthogonal arrangement of the aromatic rings. The recent synthesis of dienes such as 27 (32) has allowed us to synthesize representative members of this family.

The starting material 28 required for the synthesis of the simplest linear system, cycloproparene 29 , was prepared by allowing the diene 27 to stand with 7 for several days at $-20^{\circ} \mathrm{C}$. The resulting Diels-Alder adduct 28 can be dehydrohalogenated readily using potassium $t$-butoxide in tetrahydrofuran to give the white crystalline cycloproparene 29. These results are presented in Scheme 7.

Scheme 7

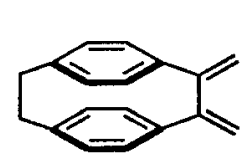

27

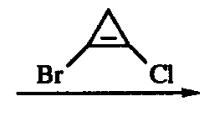

A synthesis of the nonlinear isomer $\mathbf{3 0}$ from diene 31 (33) is presented in Scheme 8.

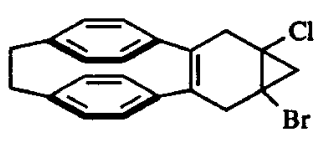

28

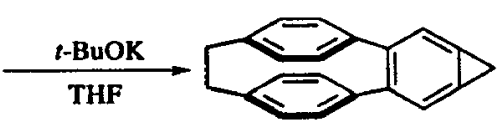

29

Scheme 8

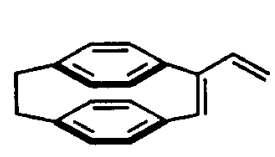

31

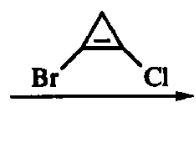

$\mathbf{X}=\mathbf{B r}$ or $\mathbf{C l}$
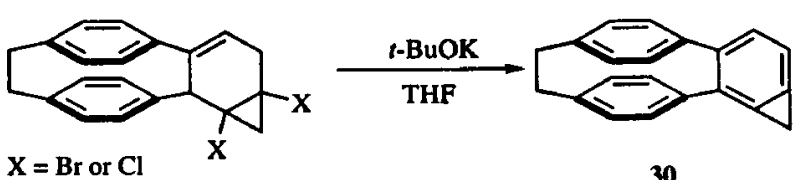

30

Finally, tetraene 32 (32) provides a route to the novel dicycloproparene 33 . Studies on the oligomerization of this cycloproparene will be carried out in the near future.

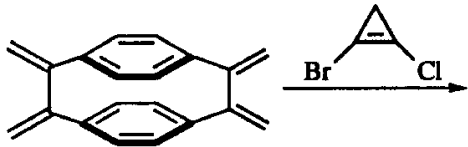

32

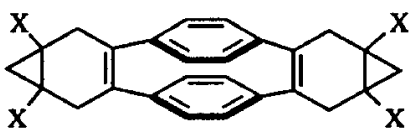

$\mathrm{X}=\mathrm{Br}$ or $\mathrm{Cl}$

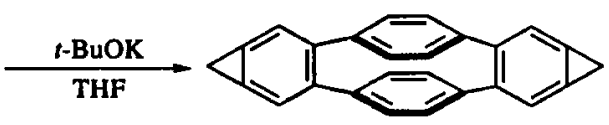

33

\section{Summary}

The above results demonstrate that bicycloproparenes and tricycloproparenes may be oligomerized readily using silver ion in chloroform. Characterization of these oligomers promises to be a long challenging task. The versatile cyclopropene synthon 1-bromo-2-chlorocyclopropene promises to have wide applicability in the synthesis of new cycloproparenes.

\section{Acknowledgments}

We gratefully acknowledge financial support from the National Science Foundation (CHE-906952) and the Robert A. Welch Foundation. Acknowledgment is made to the donors of the Petroleum Research Fund, administered by the American Chemical Society, for partial support of this research.

\section{References and Notes}

1. The publication of Feynman [Saturday Review 43, 45 (1960)] seems to have inspired much of the interest in this field of research.

2. P. W. Kenny, L. L. Miller, J. Chem. Soc. Chem. Commun. 84 (1988).

3. P. W. Kenny, L. L. Miller, S. F. Rak, T. H. Jozefiak, W. C. Christopfel, J. Am. Chem. Soc. 110, 4445 (1988).

4. A. D. Schlüter, Adv. Mater. 3, 282, (1991).

5. M. Löffler, A.-D. Schlüter, K. Gessler, W. Saenger, J.-M. Toussaint, J.-L. Brédas, Angew. Chem. Int. Ed. Engl. 33, 2209 (1994).

6. F. H. Kohnke, J. F. Stoddart, Pure and Appl. Chem. 61, 1581 (1989).

7. F. H. Kohnke, J. P. Mathias, J. F. Stoddart, Angew. Chem. Int. Ed. Engl. Adv. Mater. 28, 1103 (1989). 
9. S. Wegener, K. Müllen, Chem. Ber. 124, 2101 (1991).

10. W. E. Billups, D. J. McCord, B. R. Maughon, Tetrahedron Lett. 35, 4493 (1994).

11. For other representative reactions of strained rings with silver ion see: L. A. Paquette, S. E. Wilson, R. P. Henzel, J. Am. Chem. Soc. 94, 7771 (1972). P. G. Gassman, T. J. Atkins, J. Am. Chem. Soc. 94, 7748 (1972). P. G. Gassman, T. J. Atkins, J. Am. Chem. Soc. 93, 4597 (1971). M. Sakai, S. Masamune, J. Am. Chem. Soc. 93, 4610 (1971). M. Sakai, H. H. Westberg, H. Yamaguchi, S. Masamune, J. Am. Chem. Soc. 93, 4611 (1971). L. A. Paquette, G. R. Allen, Jr., R. P. Henzel, J. Am. Chem. Soc. 92, 7002 (1970). L. Cassar, P. E. Eaton, J. Halpern, J. Am. Chem. Soc. 92, 6366 (1970).

12. W. E. Billups, W. Y. Chow, K. H. Leavell, E. S. Lewis, J. L. Margrave, R. L. Sass, J. J. Shieh, P. G. Werness, J. L. Wood, J. Am. Chem. Soc. 95, 7878 (1973).

13. L. K. Bee, P. J. Garratt, M. M. Mansuri, J. Am. Chem. Soc. 102, 7076 (1980). See also: W. E. Billups, W. A. Rodin, J. Org. Chem. 53, 1312 (1988).

14. W. J. Bailey, Encyclopedia of Polymer Science and Engineering 2nd ed., H. F. Mark, N. M. Bikales, C. G. Overberger, G. Menges, J. I. Kroschwitz, Eds.; John Wiley and Sons, Inc: New York, pp. 158-235 (1990).

15. S. Kivelson, O. L. Chapman, Phys. Rev. B. 28, 7236 (1983).

16. K. Tanaka, K. Ohzeki, T. Yamabe, S. Yata, Synthetic Metals 9, 41 (1984).

17. A. Mishima, M. Kimura, Synthetic Metals 11, 75 (1985).

18. S. Aono, K. Nishikawa, M. Kimura, H. Kawabe, Synthetic Metals 17, 167 (1987)

19. M. Ozaki, Y. Ikeda, I. Nagoya, Synthetic Metals 28, C801 (1989); M. Ozaki, Y. Ikeda, I. Nagoya, Synthetic Metals 18, 485 (1987).

20. C. S. Marvel, C. L. Levesque, J. Am Chem. Soc. 60, 280 (1938).

21. W. J. Bailey, E. J. Fetter, J. Economy, J. Org. Chem. 27, 3479 (1962).

22. J. Kiji, M. Iwamoto, J. Polym. Sci. Polym. Lett. Ed. 6, 53 (1968).

23. J. Ippen, E. Vogel, Angew. Chem. Int. Ed. Engl. 13, 736 (1974).

24. W. E. Billups, M. M. Haley, R. C. Claussen, W. A. Rodin, J. Am. Chem. Soc. 113, 4331 (1991).

25. W. E. Billups, L.-J. Lin, B. E. Arney, Jr., W. A. Rodin, E. W. Casserly, Tetrahedron Lett. 3935 (1984).

26. Reviews: W. E. Billups, W. A. Rodin, M. M. Haley, Tetrahedron 44, 1305 (1988). B. Halton, Ind. Eng. Chem. Prod. Res. Dev. 19, 349 (1980); Chem. Rev. 89, 1161 (1989).

27. H. Hopf, D. Gottschild, W. Lenk, Isr. J. Chem. 26, 79 (1985).

28. O. Pilet, J.-L. Birbaum, P. Vogel, Helv. Chim. Acta 66, 19 (1983).

29. W. E. Billups, D. J. McCord, B. R. Maughon, J. Am. Chem. Soc. 116, 8831 (1994).

30. P. Schiess, M. Heitzmann, Helv. Chim. Acta. 61, 844 (1978).

31. Hericene was prepared as described by Köhler and Steck. See: F. H. Köhler, A. Steck, J. Organomet. Chem. 444, 165 (1993). For the first reported synthesis of hericene see: O. Pilet, J.L. Birbaum, P. Vogel, Helv. Chim. Acta 66, 19 (1983). For the origin of the name see: A. Nickon, E. Silversmith, The Name Game; Pergamon Press: New York, 1987.

32. Burkhard König, Dissertation, Universität Hamburg (1991).

33. Manfred Psiorz, Dissertation, Technische Universität Braunschweig (1983). 